\title{
Airway resistance and atopy in preschool children with wheeze and cough
}

\author{
S.A. McKenzie*, P.D. Bridge*, M.J.R. Healy**
}

Airway resistance and atopy in preschool children with wheeze and cough. S.A. McKenzie, P.D. Bridge, M.J.R. Healy. CERS Journals Ltd 2000.

ABSTRACT: The extent to which the measurement of airways resistance by the interrupter technique (Rint) distinguishes preschool children with previous wheeze from those with no respiratory symptoms and helps to classify subjects with persistent cough, was investigated.

Rint was measured before and after salbutamol treatment in 82 children with recurrent wheeze, 58 with isolated cough and 48 with no symptoms (control subjects). Their mean age (range) was 3.7 yrs $(2-<5$ yrs).

Median baseline $R$ int was higher $(\mathbf{p}<0.0001)$ in wheezers than in either coughers or control subjects $\left(1.16,0.94\right.$ and $0.88 \mathrm{kPa} \cdot \mathrm{L}^{-1} \cdot \mathrm{s}^{-1}$ respectively); coughers did not differ significantly from control subjects $(p=0.14)$. The median ratios of baseline to postsalbutamol measurements (bronchodilator response (BDR)) in the groups differed significantly (1.40, 1.27 and $1.07, p \leq 0.01$ for all), suggesting that coughers occupy an intermediate position. A BDR ratio of $>1.22$ had a specificity and sensitivity for wheeze of $80 \%$ and $76 \%$ respectively. Twenty-eight coughers had a BDR ratio $>1.22$. Wheezers' immunoglobulin $\mathbf{E}$ was inversely related to baseline $R$ int.

It is concluded that measurements of airway resistance by the interrupter technique are useful for classifying preschool children with respiratory symptoms and could be used to monitor the effect of interventions. The relation between atopy and airways resistance suggests that they have separate roles in preschool wheezing. Coughers with a high bronchodilator response could represent "cough-variant" asthma in children who have baseline airway resistance by the interrupter technique measurements similar to control subjects. Whether these children develop classical asthma will only be known at follow-up later in childhood.

Eur Respir J 2000; 15: 833-838.

Asthma is usually diagnosed only on a symptom history. The reliability of symptom reports has been questioned [1] and the need for objective measurements has been highlighted $[2,3]$. Recurrent wheeze and cough are particularly common in the preschool age group $[4,5]$. Guidelines suggest treatment with asthma medication. The effect of drugs on preschool wheeze has been judged only by change in reported symptoms $[6,7]$. Where cough is the sole complaint, the British Thoracic Society's recent guidelines state "criteria for defining asthma in the presence of chronic or recurrent cough have not been adequately defined" [8]. Clinical and epidemiological aspects of persistent cough differ from those of asthma $[9,10]$ and only the minority of night-time coughers turn out to have asthma [11]. "Cough-variant asthma" may be an asthma phenotype [12] and it seems important to identify those persistent coughers who might benefit from asthma treatment.

Until recently there has been no suitable lung function test for preschool children for ambulatory use [13]. Supposing bronchodilator response (BDR) to be one of the defining features of asthma, then if BDR could be demonstrated in children with a history of isolated cough or wheeze, then the prescribing of asthma treatment to such children could be better defended [14]. Risk factors for wheezing include small airways and atopy [15]. It has
*Queen Elizabeth Children's Service, Royal London Hospital, Whitechapel, London, UK, **Dept of Mathematical Sciences, Institute of Education, University of London, 20 Bedford Way, London, UK.

Correspondence: S.A. McKenzie, Queen Elizabeth Children's Service, Royal London Hospital, Whitechapel, London E1 1BB, UK. Fax: 442073777325

\section{Keywords: Asthma \\ cough \\ airway resistance \\ atopy \\ preschool children}

Received: June 131999

Accepted after revision January 202000

Equipment funded by GlaxoWellcome and Queen Elizabeth Hospital for Children Trustees. been proposed that poor lung function in young nonatopic wheezers represents structural, stable changes in the lung that predispose to wheezing with viral infections. If this is true and if these changes reflect airways smaller than normal, then children in this group would be expected to demonstrate high airways resistance between wheezy episodes. On the other hand, young atopic children who wheeze have normal lung function at birth [16]. Does the airway resistance in these children remain normal between wheezy episodes and do atopic children respond to bronchodilator treatment better than nonatopics who may have smaller airways? The theoretical background for measuring airways resistance using the interrupter technique (Rint) has been well described [17-20]. Using the technique, BDR testing has been undertaken in a small group of wheezy children [13]. Decrease in Rint following bronchodilator treatment could be demonstrated in most who were not wheezy at the time of the test. The hypotheses for the current study were: 1) that Rint and BDR in previously wheezy children will differ from those in control subjects; 2) that Rint in persistent coughers will identify some subjects who resemble previously wheezy children; and 3) that non-atopic previously wheezy children will have increased Rint and lower BDR than atopic children. 
The purposes of the present study were to compare baseline Rint and BDR in preschool children with a history of previous wheezing with children with no history of respiratory symptoms and children with recurrent or persistent isolated cough, and relate measurements to atopic status.

The study received approval by the local Ethics Committee.

\section{Methods}

\section{Subjects}

Control subjects were children aged $2-<5$ yrs who had no history of wheeze, recurrent or persistent cough. They were enrolled from volunteer children attending the hospital with uncomplicated problems not related to the chest.

Consecutive children aged $2-<5$ yrs attending the chest clinic who were able to undertake the test were recruited to the following groups: 1) children known to have wheezed (wheezers) in the past 6 months but not known to have wheezed in the month before testing, not wheezy at the time of recruitment and on no treatment. These children had presented with a respiratory illness to the ambulatory department at least 1 month before recruitment and had, at that time, been observed to wheeze by the doctor who examined them; 2) family practitioners were asked by letter to refer children with recurrent or persistent cough (coughers), with three episodes in the last 6 months or every day for three consecutive weeks, in the absence of fever, upper respiratory tract infection, snoring or other illness and on no treatment. Wheeze had not been reported or heard on physical examination. Apart from a history of cough, these subjects were healthy.

Baseline airways resistance by the interrupter technique and bronchodilator response testing

Rint measurements were made as previously described [13] using a single commercial device (Microlab 4000; Micromedical Ltd, Gillingham, Kent, UK) throughout the study. Before each patient was tested, volume and flow were calibrated using a precision $1 \mathrm{~L}$ syringe (Vitalograph, Buckinghamshire, UK). After a period of quiet breathing, in response to a trigger during expiration at the peak of a tidal flow, a single shutter closed automatically within 10 $\mathrm{ms}$ and stayed closed for $100 \mathrm{~ms}$. The mean of six acceptable readings was considered a measurement of $R$ int. Salbutamol, $400 \mu \mathrm{g}$ given by a $450 \mathrm{~mL}$ spacer device (Volumatic; Allen and Hanbury's, Uxbridge, Middlesex, UK), was used for all subjects for BDR testing.

Height was measured with children in stockinged feet using a wall-fixed stadiometer (Castlemead, Welwyn Garden City, Hertfordshire, UK). Serum immunoglobulin (Ig)E was measured by radioimmunoassay and skin-prick testing (SPT) to common aeroallergens (house dust mite, grass pollens, cat and dog danders and feathers) and to histamine and saline controls (Rayer Corporation, Elkhart, IN, USA) was undertaken on those coughers and wheezers who gave permission. A weal of $>3 \mathrm{~mm}$ to one prick classified a subject as SPT positive.

\section{Statistical analysis}

Data were analysed using Nanostat (AlphaBridge Ltd, London, UK). The distributions of baseline and postsalbutamol measurements were skewed to the right. Transformation to logarithms (base 10) produced a close approximation to normality [21] and rendered the standard deviations within the three subject groups approximately equal. The transformed values were analysed using Normal theory methods (t-tests, analysis of variance, simple and multiple regression), and Chi-squared and logistic regression as appropriate. BDR was the difference between the log baseline and log post-salbutamol measurements, which is the logarithm of the ratio between the original values. The sensitivity and specificity of baseline and ratio measurements were studied by constructing receiver operating curves (ROCs), in which sensitivity is plotted against (one minus specificity) from the data of wheezers and control subjects, i.e. true positives and true negatives [22]. Age-adjusted $\log \operatorname{IgE}$ was related to ageadjusted log baseline Rint and log ratio measurements.

\section{Results}

The number of control subjects recruited was 63, all of whom had baseline testing. The parents of 48 control subjects $(76 \%)$ consented to BDR testing. There were missing values for heights in six control subjects. There were 58 coughers and 82 wheezers, all of whom had baseline and BDR testing. There was a missing height measurement in one cougher. Table 1 shows the subjects' age, height and sex in the three groups. There were no significant differences between the groups.

\section{Baseline, post-salbutamol and bronchodilator response measurements}

Table 2 and figure 1 show measurements of baseline, post-salbutamol Rint and ratios for children in the three groups who had both measurements. Table 2 gives medians and quartiles obtained by back-transforming the estimates obtained using the logged data.

Effects of age, height and sex on baseline airway resistance by the interrupter technique, post-salbutamol airway resistance by the interrupter technique and bronchodilator response

The effects of age and height were investigated by fitting regression equations for age (fig. 2), the slopes in the three

Table 1. - Age, height and sex of subjects

\begin{tabular}{lccc}
\hline & $\begin{array}{c}\text { Control } \\
\text { subjects }\end{array}$ & Coughers & Wheezers \\
\hline $\mathrm{n}$ & 63 & 58 & 82 \\
Males:females & $30: 33$ & $29: 29$ & $51: 31$ \\
Mean \pm SD age yrs & $3.8 \pm 0.72$ & $3.7 \pm 0.90$ & $3.6 \pm 0.86$ \\
$\mathrm{n}$ & 57 & 57 & 82 \\
Mean \pm SD height $\mathrm{cm}$ & $101.3 \pm 6.2$ & $102.3 \pm 8.7$ & $100.1 \pm 7.2$ \\
\hline
\end{tabular}

Coughers: subjects with three coughing episodes in the last 6 months or every day for three consecutive weeks; wheezers: subjects who wheezed in the past 6 months but not known to have wheezed in the month before testing. 
Table 2. - Baseline and post-salbutamol airways resistance by the interrupter technique (Rint) measurements, bronchodilator response (BDR) and immunoglobulin (Ig)E measurements

\begin{tabular}{lrrcc}
\hline & $\mathrm{n}$ & Median & $\begin{array}{r}\text { Lower } \\
\text { quartile }\end{array}$ & $\begin{array}{c}\text { Upper } \\
\text { quartile }\end{array}$ \\
\hline Baseline $R$ int $\mathrm{kPa} \cdot \mathrm{L}^{-1} \cdot \mathrm{s}^{-1}$ & & & & \\
$\quad$ Control subjects & 63 & 0.88 & 0.74 & 1.06 \\
$\quad$ Coughers & 58 & 0.94 & 0.81 & 1.10 \\
$\quad$ Wheezers & 82 & 1.16 & 0.95 & 1.43 \\
Post-salbutamol Rint $\mathrm{kPa} \cdot \mathrm{L}^{-1} \cdot \mathrm{s}^{-1}$ & & & \\
$\quad$ Control subjects & 48 & 0.79 & 0.65 & 0.97 \\
$\quad$ Coughers & 58 & 0.74 & 0.63 & 0.88 \\
$\quad$ Wheezers & 82 & 0.83 & 0.69 & 1.00 \\
Ratio Baseline/post-salbutamol & & & \\
$\quad$ Control subjects & 48 & 1.07 & 0.97 & 1.17 \\
$\quad$ Coughers & 58 & 1.27 & 1.10 & 1.47 \\
$\quad$ Wheezers & 82 & 1.40 & 1.22 & 1.60 \\
IgE IU.mL & & & & \\
$\quad$ Coughers & 40 & 42 & 13 & 137 \\
$\quad$ Wheezers & 61 & 98 & 30 & 316 \\
\hline
\end{tabular}

Coughers: subjects with three coughing episodes in the last 6 months or every day for three consecutive weeks; wheezers: subjects who wheezed in the past 6 months but not known to have wheezed in the month before testing.

groups did not differ significantly $\left(\mathrm{F}^{2}{ }_{197}=1.70, \mathrm{p}=0.19\right)$, the common slope being -0.0719 , SEM $0.0088, \mathrm{p}<0.0001$. This implies a decrease in Rint of $18 \% \cdot \mathrm{yr}^{-1}$ in the age range $2-<5$ yrs. The effect of height was similar and there was no significant effect of sex. The BDR (log ratio) variable did not depend significantly upon age, height or sex.

\section{Differences between measurements in the three groups}

Log baseline and log post-salbutamol measurements were adjusted for age. At baseline, the coughers did not significantly alter from the control subjects (log difference 0.024 , SEM $0.018, p=0.18$ ) but the mean for the wheezers was significantly greater than those of the other two groups

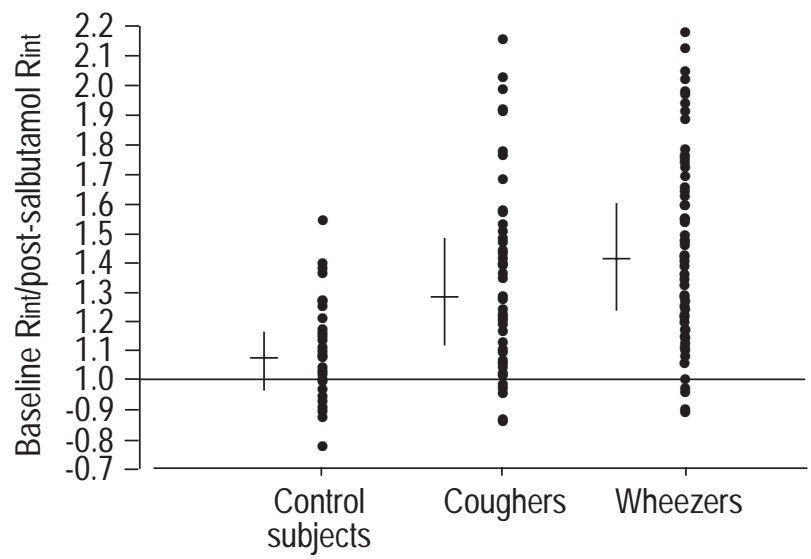

Fig. 1. - Ratio of baseline airway resistance by the interrupter technique (Rint) to post-salbutamol Rint. Bronchodilator response in control subjects $(n=48)$, coughers $(n=58)$ and wheezers $(n=82)$ with median values, lower and upper quartiles. See legend to table 2 for definitions.

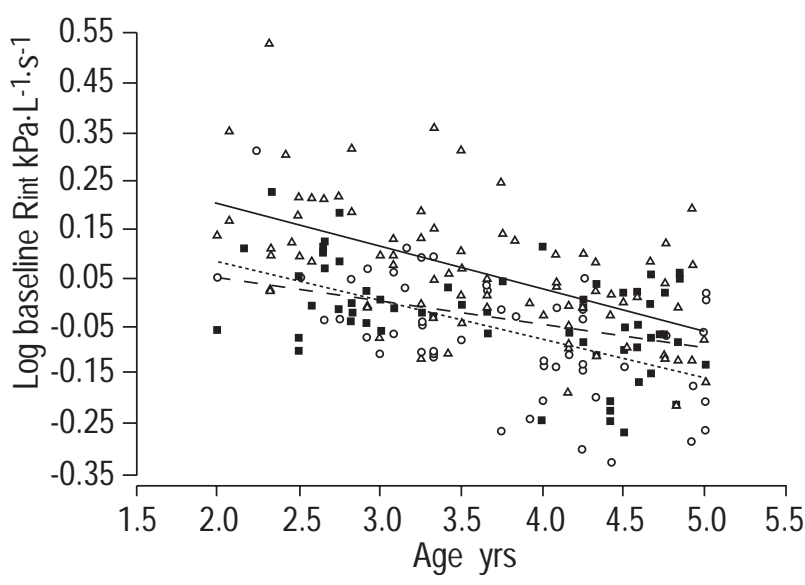

Fig. 2. - Relationships between log baseline airway resistance by interrupter technique (Rint) and age. $\bigcirc$ : control subjects; $\square$ : coughers; $\triangle$ : wheezers. …...: control subjects, $\mathrm{y}=-0.078 \times+0.24$; ------: coughers, $\mathrm{y}=-0.049 \times+0.16$; — : wheezers, $\mathrm{y}=-0.066 \times+0.38$. See legend to table 2 for further definitions.

(log difference from control subjects 0.105 , SEM 0.018 , $\mathrm{p}<0.0001, \log$ difference from coughers 0.082 , SEM 0.018 , $\mathrm{p}<0.0001)$.

Post-salbutamol, the control subjects did not differ significantly from the other two groups (log difference from coughers 0.028 , SEM $0.020, \mathrm{p}=0.16, \log$ difference from wheezers 0.009 , SEM $0.019, \mathrm{p}=0.65$ ) but the mean log Rint measurement of the coughers was just below that of the wheezers (log difference 0.037, SEM 0.018, $\mathrm{p}=0.04$ ).

The ratios of baseline to post-salbutamol are shown in figure 1 . The control mean was very significantly lower than those of the other groups (log difference from coughers 0.075 , SEM $0.016, p<0.0001)$, while the coughers' mean was lower than that of the wheezers' (log difference 0.042 , SEM $0.016, p=0.01)$. The $\log$ ratio did not correlate significantly with the mean of log baseline and log postsalbutamol (overall Rint) in any of the three groups ( $\mathrm{r}=$ $-0.10,0.083$ and $0.10, \mathrm{p}=0.51,0.54$, and 0.38 ).

\section{Receiver operating curves}

There was overlap of both baseline and BDR (ratio) measurements in the wheeze and control groups (table 2 and fig. 1). The ROCs, by demonstrating sensitivity and specificity of measurements in previously wheezy subjects (wheezing heard on examination by a doctor), describe this overlap. The data for these curves (fig. 3) were derived from the estimated means and standard deviations of the baseline and BDR variables. The ROC for the baseline measurements was adjusted for age. These curves suggest that the BDR measurement is a better discriminator between positive and negative wheezers than the baseline.

For $80 \%$ specificity, a baseline measurement $>1.45$ $\mathrm{kPa} \cdot \mathrm{L}^{-1} \cdot \mathrm{s}^{-1}$ is needed. This has a sensitivity of $60 \%$. Applying this threshold value to the coughers, two of 58 subjects had measurements above this value. For $80 \%$ specificity, a BDR measurement $>1.2$ is needed. This has a sensitivity of $76 \%$. Of the 58 coughers, 28 had BDR measurements above this value. 


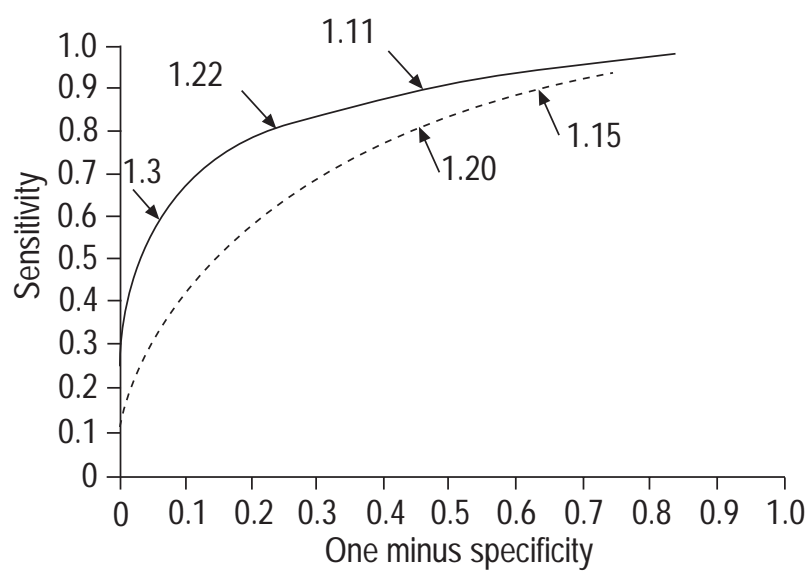

Fig. 3. - Baseline airway resistance by interrupter technique (Rint; - - -) and bronchodilator response (BDR; - ) receiver operating curves show that, for a given specificity, BDR is the measurement with better sensitivity. Values $\left(\mathrm{kPa} \cdot \mathrm{L}^{-1} \cdot \mathrm{s}^{-1}\right)$ of baseline Rint and BDR are shown for $80 \%$ and $90 \%$ sensitivity, and also $60 \%$ for BDR.

Relationship of atopic status to baseline airway resistance by the interrupter technique and bronchodilator response

The atopic status of control subjects was not known. Serum measurements of $\operatorname{IgE}$ were available for 41 coughers and 60 wheezers. These were transformed to log values (base 10) for analyses. IgE measurements increased significantly with age (regression coefficient $=0.244$, SEM $=$ $0.082, \mathrm{p}=0.004)$. Wheezers had significantly higher $\operatorname{IgE}$ measurements than coughers (table $2 ; \mathrm{p}=0.002$ ), and this difference remained significant after age was taken into account $(\log$ difference $=0.39$, SEM $0.15, p=0.01)$. There was no significant relationship between age-adjusted $\operatorname{IgE}$ measurements in coughers and either age-adjusted log baseline $R$ int or $\log$ ratio Rint, (regression coefficient for baseline -0.0177 , SEM $0.0191, \mathrm{p}=0.36$; regression coefficient for ratio 0.0132 , SEM $0.0175, \mathrm{p}=0.45$ ). While there was no relationship between age-adjusted $\operatorname{IgE}$ and $\log$ ratio measurements (regression coefficient $=-0.0198$, SEM $0.0147, \mathrm{p}=0.18$ ), there was a significant inverse relation-

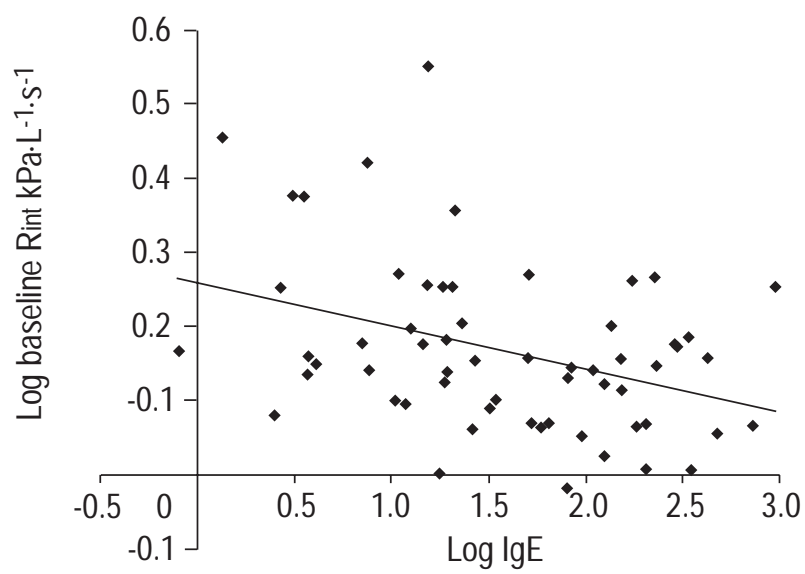

Fig. 4. - Age-adjusted log immunoglobulin (Ig)E and age-adjusted log baseline airway resistance by interrupter technique (Rint) in wheezers. $y=-0.0550 \times+0.2615, p=0.005$. The diagonal line represents the regression line. See legend to table 2 for further definitions. ship between age-adjusted $\log \operatorname{IgE}$ and age-adjusted $\log$ baseline Rint in wheezers (fig. 4) (regression coefficient 0.0550 , SEM 0.0190, $\mathrm{p}=0.005$ ).

SPT was undertaken in 31 coughers and 41 wheezers. There was no significant difference in the percentage of coughers $(39 \%)$ and wheezers $(41 \%)$ who were SPT positive $(\mathrm{p}=0.81)$. There was no relationship between age adjusted $\log$ baseline or $\log$ ratio Rint measurements and positive SPT in coughers or wheezers.

\section{Discussion}

Reported wheeze remains the cornerstone of the epidemiological assessment of asthma [23, 24]. Because of the concern that there is reporting bias of respiratory symptoms such as wheeze [25] and uncertainty as to whether persistent cough should be considered asthma [12], the need for objective testing for asthma in preschool children as well as school children is compelling [33]. There is debate about the diagnostic value of tests of bronchial hyperresponsiveness (BHR) [26] and to date there are no satisfactory diagnostic tests using inflammatory markers. It is possible to test BHR in this age group [27] but to the authors' knowledge, the success of this technique in a busy ambulatory setting has not been described. The feasibility and practicality of Rint have been described here and it was shown that full BDR testing can be undertaken successfully in $53 \%, 71 \%$ and $91 \%$ of subjects in the $2-$ $<3,3-<4$ and $4-<5$ yr age groups respectively [13]. There appears to be broad agreement that asthmatics have reversible airways narrowing, at least at some time in the course of their disease. The current study examines this aspect of asthma in preschool children.

This study has shown that baseline Rint in a group of preschool children who have been observed to have wheezed in the 6 months before testing but not in the month before testing is significantly higher on average than in a group of children with no respiratory symptoms. Baseline $R$ int in a group with recurrent cough did not differ significantly from those with no history of respiratory symptoms but there was a large difference between coughers and wheezers so that baseline Rint measurements in coughers resembled control subjects more than wheezers. Baseline measurements were negatively related to age but the mean ages of the groups were similar so that age accounts for very little of any difference. The post-salbutamol measurements were similar in all three groups suggesting that there is little evidence that for most subjects at this age there is irreversible damage. It would be interesting and important to know whether those subjects with high postsalbutamol measurements continued to have high airways resistance.

Age and height predicted the baseline measurements to a very similar degree. Age is simpler to determine under clinical conditions and the authors suggest that it be used rather than height. This means that Rint could be a very suitable tool for epidemiology studies.

The correct way to describe BDR has been widely discussed [28-30]. For the current study the ratio of baseline measurement to post-salbutamol measurement was chosen to describe BDR data. BDR measurements differed significantly between all three groups. BDR was significantly increased in coughers compared to control subjects, in contrast to the comparison of baseline measurements 
which were similar. Post-salbutamol measurements in coughers were lower than in control subjects but not significantly. However, they were significantly lower than in wheezers. There was no correlation between BDR with the age-adjusted level of overall Rint (measured as the mean of pre and post measurements). (It is known that spurious correlations are obtained if measurements of change, such as the log ratio, are related to the final values [31]) so that there was not a significant tendency for children within a group who had high Rint measurements to show high reversibility when measured in ratio terms.

Recent studies of persistent cough suggest that children with this symptom do not resemble asthmatics as previously supposed [9-11, 32]. Nevertheless, it seems reasonable to consider that some children reported to have persistent or recurrent cough would have poorly perceived wheeze. Objective testing could help to distinguish those children with "cough-variant" asthma and in whom asthma treatment should be considered from those who do not have "cough-variant" asthma. Parents know when their children are coughing although they do not know how much [33] and so recruiting children to a study on the basis of parents' reports of persistent cough is reasonable. The inclusion criteria for this group included wheeze never having been reported or heard. The authors chose to recruit children to the "wheezer" group only if they had been heard to wheeze on examination by a doctor. This was the gold standard for asthma for the current purposes. Similarly, children who had never had persistent respiratory symptoms of cough or wheeze and were well at the time of the study were the gold standard for nonasthmatics. The ROCs for baseline and BDR in control subjects and wheezers suggest that BDR is the more discriminating. For epidemiology studies, where parents and children may not agree to being given bronchodilator ( $24 \%$ of those who undertook baseline testing were unwilling in this study) and baseline measurements are all that can be ob-tained, a reduction in specificity may have to be accepted to maintain sensitivity. In practice, if children who are asymptomatic have baseline measurements higher than the selected threshold, parents and children may reconsider BDR testing. At least then the children can be identified for follow-up.

Other techniques have been used to measure baseline resistance and BDR in children. Using the forced oscillation technique, a change of $19 \%$ resistance was considered to represent BDR in a group wheezy at the time of the test [34]. The same measurements in healthy children and stable asthmatics using the impulse oscillation technique did not distinguish between the groups [35]. Half of the asthmatics were on treatment. A change in resistance of $>40 \%$ was considered to represent reversibility. Wheezers in the present study differ from those in the study by HELLINCKX et al. [35] as they were on no treatment.

$\mathrm{IgE}$ measurements were higher in the wheezers than in the coughers. This has been noted previously [10]. IgE measurements were inversely related to baseline measurements in the wheezers after age-adjustment. In fact, the wheezers with the highest IgE had age-adjusted baseline measurements comparable to those in the control group. If serum $\operatorname{IgE}$ is assumed to reflect atopy, then the less atopic wheezers would appear to have higher airway resistance and this could reflect smaller airways, some- thing which has been previously suggested [16]. IgE was not related to BDR in either coughers or wheezers. Whether treatments other than bronchodilators, such as corticosteroids alter Rint measurements and BDR in atopic and nonatopic children, needs now to be examined. SPT results were not significantly related to any Rint measurement. This could reflect the small number of subjects who agreed to SPT or to delay in the development in SPT positivity to inhaled allergens [36].

In summary, the differences between baseline airway resistance by the interrupter technique and bronchodilator response were measured in groups of preschool children with no history of respiratory symptoms (control subjects), children with persistent isolated cough (coughers) and children who have been observed to wheeze at least 1 month previous to testing (wheezers). Although coughers did not have significantly higher baseline airway resistance by the interrupter technique values than control subjects, many responded to salbutamol to an extent comparable with children with previous wheeze. Whether their symptoms respond to regular bronchodilator or other asthma treatment is not known. Coughers as a group, respond poorly or not at all [36-38] but perhaps those with high bronchodilator response measurements would benefit. The airway resistance by the interrupter technique is ready to be used to help classify children with vague respiratory symptoms. It could also be used as a tool in preschool children with cough and wheeze to measure change in lung function in response to interventions.

\section{References}

1. Magnus P, Jaakkola JJ. Secular trend in the occurrence of asthma among children and young adults: critical appraisal of repeated cross sectional surveys. BMJ 1997; 314 : 1795-1799.

2. Toelle BG, Peat JK, Salome CM, Mellis CM, Woolcock AJ. Toward a definition of asthma for epidemiology. Am Rev Respir Dis 1992; 146: 633-637.

3. von Mutius E. Air pollution and asthma-fact or artifact? A plea for inclusion of objective measures in environmental epidemiology. Pediatr Pulmonol 1998; 25: 297-298.

4. Toop LJ, Howie JG, Paxton FM. Night cough and general practice research. $J R$ Coll Gen Pract 1986; 35: 74-77.

5. Clifford RD, Howell JB, Radford M, Holgate ST. Associations between respiratory symptoms, bronchial response to methacholine, and atopy in two age groups of schoolchildren. Arch Dis Child 1980; 64: 1133-1139.

6. Wilson N, Sloper K, Silverman M. Effect of continuous treatment with topical corticosteroid on episodic viral wheeze in preschool children. Arch Dis Child 1995; 72: 317-320.

7. Van Bever HP, Schuddinck L, Wojciechowski M, Stevens WJ. Aerosolized budesonide in asthmatic infants: a double blind study. Pediatr Pulmonol 1990; 9: 177-180.

8. British Thoracic Society, National Asthma Campaign, Royal College of Physicians, London. The British Guidelines on Asthma Management. 1995 Review and Position statement. Thorax 1997; 52 (Suppl. 1): S9.

9. Kelly YJ, Brabin BJ, Milligan PJ, Reid JA, Heaf D, Pearson MG. Clinical significance of cough and wheeze in the diagnosis of asthma. Arch Dis Child 1996; 75: 488493.

10. Wright AL, Holberg CJ, Morgan WJ, Taussig LM, Halonen M, Martinez FD. Recurrent cough in childhood 
and its relation to asthma. Am J Respir Crit Care Med 1996; 153: 1259-1265.

11. Ninan TK, Macdonald L, Russell G. Persistent nocturnal cough in childhood: population based study. Arch Dis Child 1995; 73: 403-407.

12. McKenzie SA. Cough - but is it asthma? Arch Dis Child 1994; 70: 1-2.

13. Bridge PD, Ranganathan S, McKenzie SA. The measurement of airway resistance using the interrupter technique ( $R$ int) in preschool children in the ambulatory setting. Eur Respir J 1999; 13: 792-796.

14. Picciotto A, Hubbard M, Sturdy P, Naish J, McKenzie SA. Prescribing for persistent cough in children. Respir Med 1998; 92: 638-641.

15. Martinez FD, Helms PJ. Types of asthma and wheezing. Eur Respir J 1998; 12: Suppl. 27 53-58.

16. Martinez FD, Wright AL, Taussig LM, Holberg CJ, Halonen M, Morgan WJ. Asthma and wheezing in the first six years of life. New Engl J Med 1995; 332: 133138.

17. Carter ER Stecenko AA, Pollock BH, Jaeger MJ. Evaluation of the interrupter technique for the use of assessing airway obstruction in children. Pediatr Pulmonol 1994; 17: 211-217.

18. Phagoo SB, Wilson NM, Silverman M. Evaluation of a new interrupter device for measuring bronchial responsiveness and the response to bronchodilator in 3 year old children. Eur Respir J 1996; 9: 1374-1380.

19. Oswald-Mammosser M, Llerena C, Speich JP, Donata L, Lonsdorfer. Measurements of respiratory system resistance by the interrupter technique in healthy and asthmatic children. Pediatr Pulmonol 1997; 24: 78-85.

20. Bridge PD, Silverman M. A portable device based on the interrupter technique to measure bronchodilator response in schoolchildren. Eur Respir J 1996; 9: 1368-1373.

21. Healy MJR. The disciplining of medical data. Br Med Bull 1968; 24: 210-214.

22. Altman DG. Some common problems in medical research. In: Altman DG, ed. Practical Statistics for Medical Research, 1st Edn. London, UK, Chapman and Hall, 1994; pp. 417-418.

23. Anderson HR, Butland BK, Strachan DP. Trends in prevalence and severity of childhood asthma. BMJ 1994; 308: 1600-1604.

24. Kemp T, Pierce N, Crane J, Beasley R. Problems of measuring asthma prevalence. Respirology 1996; 3: 183-188.
25. Taylor DR. Making the diagnosis of asthma. BMJ 1997; 315: 4-5.

26. Wilson N, Silverman M. Bronchial responsiveness and its measurement. In: Childhood Asthma and other Wheezing Disorders. London, UK, Chapman and Hall, 1995; pp. 141-174.

27. Wilson NM, Bridge P, Phagoo SB, Silverman M. The measurement of methacholine bronchial responsiveness in 5 year old children: three methods compared. Eur Respir J 1995; 8: 364-370.

28. Waalkens HJ, Merkus PJ, Van Essen-Zandvliet EE, et al. Assessment of bronchodilator response in children with asthma. Eur Respir J 1993; 6: 645-651.

29. van Noord JA, Smeets J, Clement J, van de Woestijne KP, Demedts M. Assessment of reversibility of airflow obstruction. Am J Respir Crit Care Med 1994; 150: 551554.

30. Demedts M. The assessment of reversibility: what physiological tests? Eur Respir J 1990; 3: 1084-1087.

31. Oldham PD. In: Silverman M. Measurement in Medicine. 1st Edn. London, UK, English Universities Press, 1968; pp. 198-199.

32. Faniran AO, Peak JK, Woolcock AJ. Persistent cough in asthma: is it asthma? Arch Dis Child 1998; 79: 411414.

33. Fuller P, Picciotto A, Davies M, McKenzie SA. Cough and sleep in inner-city children. Eur Respir J 1998; 12: 426-431.

34. Ducharme FM, Davis GM. Respiratory resistance in the emergency department: a reproducible and responsive measure of asthma severity. Chest 1997; 113: 1566-1572.

35. Hellinckx J, De Boeck K, Bande-Knops J, van der Poel M, Demedts M. Bronchodilator response in 3-6.5 year old healthy and stable asthmatic children. Eur Respir $J$ 1998; 12: 438-443.

36. van Asperen PP, Kemp AS. The natural history of IgE sensitisation and atopic disease in early childhood. Acta Paediatr Scand 1989; 78: 239-245.

37. Chang AB, Phelan PD, Carlin JB, Sawyer SM, Robertson CF. A randomized, placebo controlled trial of inhaled salbutamol and beclomethasone for recurrent cough. Arch Dis Child 1998; 79: 6-11.

38. Davies MJ, Fuller P, Picciotto A, McKenzie SA. Persistent cough in children: a randomised trial of highdose inhaled corticosteroids. Arch Dis Child 1999; 81: $38-44$. 